\title{
Apixaban for Treating Venous Thromboembolism in Real-World Clinical Practice
}

\author{
Manuel Monreal ${ }^{1}$ \\ ${ }^{1}$ Hospital Universitari Germans Trias I Pujol, Badalona, Spain \\ Thromb Haemost 2018;118:1850-1851.
}

In recent years, the landscape for management of venous thromboembolism (VTE) has changed with the introduction of the direct oral anticoagulants (DOACs, also known as nonvitamin $\mathrm{K}$ antagonist oral anticoagulants). ${ }^{1,2}$ Current guidelines of antithrombotic therapy recommend the use of dabigatran, rivaroxaban, apixaban or edoxaban in patients with VTE. ${ }^{3}$ The risk reduction of recurrent VTE with the DOACs is similar to the risk reduction with low-molecularweight heparin and vitamin K antagonists (VKAs), while the risk of bleeding is less with the DOACs. ${ }^{4-9}$ Indeed, in an analysis of bleeding events from EINSTEIN, AMPLIFY and HOKUSAI-VTE trials, factor Xa inhibitor associated major bleeding events had a significantly less severe presentation and a similar course compared with VKA. ${ }^{10}$

However, the pivotal trials where their indication was based on applied strict exclusion criteria, aimed to exclude patients at increased risk for bleeding. They slightly varied from each other, but in general patients were excluded if they had the following: (1) cancer requiring over 6 months of anticoagulant therapy or with a life expectancy of 3 to 6 months; (2) creatinine clearance levels $<30 \mathrm{~mL} / \mathrm{min}$; (3) a high risk of bleeding; (4) clinically significant liver disease or (5) pregnancy.

In the Registro Informatizado de la Enfermedad TromboEmbólica (RIETE) real-life registry, one in every five patients (19\%) with VTE had at least one of the above-mentioned exclusion criteria. ${ }^{11}$ Not unexpectedly, these patients had a fourfold higher rate of major bleeding (sixfold higher rate of fatal bleeding) and a threefold higher rate of VTE recurrences (fourfold higher rate of fatal pulmonary embolism [PE]) than those without exclusion criteria. Hence, before prescribing DOACs to VTE patients in real life, the advantages of the DOACs over conventional therapy must be confirmed in real-world population.

In this issue of Thrombosis and Haemostasis, Weycker et al ${ }^{12}$ report an observational study comparing the effectiveness and safety of apixaban versus warfarin for the long-term therapy of VTE in real life. Investigators used data from four U.S. private

received

September 27, 2018

accepted after revision

September 27, 2018

Address for correspondence Manuel Monreal, MD, PhD, Hospital Universitari Germans Trias I Pujol, Badalona, Spain (e-mail: manuel.monreal@uab.cat).

health care claims databases from September 2014 to June 2017. After propensity score matching, 17,878 patients receiving long-term therapy with apixaban were compared with 17,878 patients on warfarin. During a mean follow-up of 5 months, patients receiving apixaban had a significantly lower risk for VTE recurrences (hazard ratio [HR]: 0.80), major bleeding (HR: 0.75) and/or clinically relevant non-major bleeding (HR: 0.77) than those on warfarin. Despite some differences in study design, methods and clinical characteristics of the patients (they were older and more likely to have initially presented with PE or to have provoked VTE), these findings are consistent with those in the pivotal Phase III clinical trial (AMPLIFY). ${ }^{7}$

Strengths of the analysis include that a large number of unselected patients were enrolled. However, there are several limitations, as acknowledged in the manuscript. First, the diagnoses of major bleeding and recurrent VTE were not always confirmed by objective methods, and thus their accuracy is unknown. Second, the authors cannot determine the exact doses and regimens (i.e. once vs. twice daily) of the drugs. In the RIETE registry, one in every two to three patients receiving apixaban was prescribed the drug at doses and/or regimen different from those recommended in the product label. ${ }^{13}$ This is important since the use of non-recommended doses of DOACs did not reduce the risk of bleeding, but increased the risk of VTE recurrences. Third, since the study does not include full information on mortality, death was not treated as a competing risk, which may influence risks of the outcomes.

The use of DOACs in patients with VTE is progressively increasing over time, but their prescription in patients with exclusion criteria to be recruited in the pivotal trials represents a major challenge due to the lack of evidence on their efficacy and safety. Data from RIETE and PREFER in VTE registries reported that the use of DOACs was less likely in patients with cancer, renal insufficiency or at increased risk for bleeding, and this seems paradoxical since its use has been associated with less bleeding in randomized trials. ${ }^{11,14}$ It would seem to

(c) 2018 Georg Thieme Verlag KG Stuttgart · New York
DOI https://doi.org/ 10.1055/s-0038-1675241. ISSN 0340-6245. 
be more cost-effective to prescribe safer drugs in patients at increased risk for bleeding. In one of these studies, ${ }^{11}$ no VTE patients with severe renal insufficiency $(n=56)$ or metastatic cancer $(n=45)$ receiving DOACs for long-term therapy suffered major bleeding, thus suggesting that the DOACs may be at least as safe as standard therapy in these scenarios. Moreover, six pregnant women were prescribed DOACs, when the use of DOACs is formally contraindicated during pregnancy. The International Society on Thrombosis and Haemostasis issued a guidance document that recommended the immediate discontinuation of DOACs after confirmation of pregnancy. ${ }^{15}$

Since randomized clinical trials are not allowed in patients with severe renal insufficiency, pregnancy or at high risk of bleeding, we will need to adjust our prescriptions according to forthcoming evidence from real-life studies.

\section{Conflict of Interest}

None.

\section{References}

1 Schulman S, Ageno W, Konstantinides SV. Venous thromboembolism: past, present and future. Thromb Haemost 2017;117(07): 1219-1229

2 Schulman S, Singer D, Ageno W, Casella IB, Desch M, Goldhaber SZ. NOACs for treatment of venous thromboembolism in clinical practice. Thromb Haemost 2017;117(07):1317-1325

3 Kearon C, Akl EA, Ornelas J, et al. Antithrombotic therapy for VTE disease: Chest Guideline and Expert Panel Report. Chest 2016;149 (02):315-352

4 Schulman S, Kearon C, Kakkar AK, et al; RE-COVER Study Group. Dabigatran versus warfarin in the treatment of acute venous thromboembolism. N Engl J Med 2009;361:2342-2352

5 Bauersachs R, Berkowitz SD, Brenner B, et al; EINSTEIN Investigators. Oral rivaroxaban for symptomatic venous thromboembolism. N Engl J Med 2010;363(26):2499-2510
6 Büller HR, Prins MH, Lensin AW, et al; EINSTEIN-PE Investigators. Oral rivaroxaban for the treatment of symptomatic pulmonary embolism. N Engl J Med 2012;366(14):1287-1297

7 Agnelli G, Buller HR, Cohen A, et al; AMPLIFY Investigators. Oral apixaban for the treatment of acute venous thromboembolism. N Engl J Med 2013;369(09):799-808

8 Büller HR, Décousus H, Grosso MA, et al; Hokusai-VTE Investigators. Edoxaban versus warfarin for the treatment of symptomatic venous thromboembolism. N Engl J Med 2013;369(15):1406-1415

9 Gómez-Outes A, Lecumberri R, Suárez-Gea ML, Terleira-Fernández AI, Monreal M, Vargas-Castrillón E. Case fatality rates of recurrent thromboembolism and bleeding in patients receiving direct oral anticoagulants for the initial and extended treatment of venous thromboembolism: A systematic review. J Cardiovasc Pharmacol Ther 2015;20(05):490-500

10 Bleker SM, Brekelmans MPA. , Eerenberg ES, et al. Clinical impact of major bleeding in patients with venous thromboembolism treated with factor Xa inhibitors or vitamin $\mathrm{K}$ antagonists. Thromb Haemost 2017;117(10):1944-1951

11 Moustafa F, Pesavento R, di Micco P, et al; RIETE Investigators. Real-life use of anticoagulants in venous thromboembolism with focus on patients with exclusion criteria for direct oral anticoagulants. Clin Pharmacol Ther 2018;103(04):684-691

12 Weycker D, Li X, Wygant GT, et al. Effectiveness and safety of apixaban versus warfarin as outpatient treatment of venous thromboembolism in US clinical practice. Thromb Haemost 2018;118(11). Doi: 10.1055/s-0038-1673689

13 Trujillo-Santos J, Di Micco P, Dentali F, et al; RIETE Investigators. Real-life treatment of venous thromboembolism with direct oral anticoagulants: the influence of recommended dosing and regimens. Thromb Haemost 2017;117(02):382-389

14 Cohen AT, Gitt AK, Bauersachs R, et al. The management of acute venous thromboembolism in clinical practice. Results from the European PREFER in VTE Registry. Thromb Haemost 2017;117 (07):1326-1337

15 Cohen H, Arachchillage DR, Middeldorp S, Beyer-Westendorf J, Abdul-Kadir R. Management of direct oral anticoagulants in women of childbearing potential: guidance from the SSC of the ISTH. J Thromb Haemost 2016;14(08):1673-1676 